\title{
A model for estimating flood damage in Italy: preliminary results
}

\author{
F. Luino, M. Chiarle, G. Nigrelli, A. Agangi, M. Biddoccu, \\ C. G. Cirio \& W. Giulietto \\ Consiglio Nazionale delle Ricerche, \\ Istituto di Ricerca per la Protezione Idrogeologica , Turin, Italy
}

\begin{abstract}
Floods are a very common natural process in Italy. In the 20 -year period from 1980 to 2000 the State set aside 7,400 million euro for flood damage, or roughly one million euro per day. With this study we developed a flood damage estimation model which land administration bodies and insurance companies could find useful in the management of flood-related damage data. The model simulates event scenarios and evaluates expected economic losses. Potential economic loss assessment implies knowledge of the event, exposed asset values and the degree of damage. Following a widely shared simplifying assumption, flood water level was taken as the only factor indicating event magnitude. The model incorporates the following steps:

a) event description: definition of flood parameters (flooded area and water level), utilizing real-time measurements or data from event simulation with a hydraulic model;

b) asset damage and identification of the affected population;

c) evaluation of the degree of damage as a function of event magnitude;

d) attribution of an economic value to different exposed assets;

e) quantification of economic loss by multiplying economic losses and damage severity.

The method could be used either as a forecasting tool to define event scenarios or for "real-time" damage assessment after a catastrophe. The approach is suitable primarily to large-area damage assessment but could also be appropriate for land use planning, civil protection, and risk mitigation.

Keywords: flood, damage evaluation, stage-damage curves, Northern Italy.
\end{abstract}




\section{Introduction}

Floods affect more people worldwide than any other form of natural process. In the last 15 years severe hydrological events have struck Italy 7 times, taking high tolls in damage and human lives. Despite extensive flood management efforts, flood damage is increasing owing mainly to augmented human pressure on the environment, with a reduction in natural areas around watercourses.

In Italy, 783 agencies deal in some way with the economics of floods. The various agencies have an ordinary management, but after a disaster they can operate extraordinary competences. For all these agencies flood damage evaluation is highly important: rapid assessment of damage has to be done before repair interventions can be started. Usually, damage evaluation is conducted by expert visual inspection, but collecting comprehensive damage information in an affected area also takes time. A longer evaluation will sometimes produce very different results from those obtained in a short evaluation because of limited inspection items.

\section{Conceptual framework}

In 2004 the European Community initiated the "DAMAGE" project in response to the need of European civil protection services to have a common methodology for the evaluation of the damage produced by a disaster (Damage Project [1]). One of the project's aims is to provide public administrations (e.g. municipal, provincial and regional governments) with a management tool for damage information. For this purpose a GIS-based model was created that can simulate flood events and evaluate subsequent economic losses.

The traditional approach to damage assessment consists of detailed field survey to establish the actual loss. In recent years attempts have been made to define methodologies for rapid assessment of damage in the aftermath of a catastrophe.

The main objective of our study was to devise a method that could enable real-time assessment of potential economic direct loss due to a catastrophe. The method is based on a thorough knowledge of the local area coupled with a description of some physical features of the natural event.

Given a catastrophic natural event of given intensity affecting a given area, the worth of economic losses connected to direct damages to goods depends on the number and the economic value of the units of each element in the area and on the degree of damage to the exposed units (varying from $0=$ undamaged to $1=$ completely destroyed).

The economic worth of loss can be defined as:

$$
\begin{gathered}
\text { DIRECT ECONOMIC LOSS }= \\
\Sigma_{\mathrm{i}}\left(\text { UNIT VALUE }_{\mathrm{i}} * \mathrm{~N}^{\circ} \text { units EXPOSED ELEMENT } \text { ELAMAGE DEGREE }_{\mathrm{i}}[\%]\right)
\end{gathered}
$$

DAMAGE $=$ State of a building or system after a disaster (GeoRisk [2]). LOSS = Effect and impact of damage (GeoRisk [2]). 
EXPOSED ELEMENTS = Population, property, economic activity, public services, environmental goods and cultural heritage items in a location exposed to danger.

DAMAGE DEGREE $=$ VULNERABILITY $=$ Degree of loss of one or more elements at risk resulting from a dangerous phenomenon with a given intensity and duration. This is a function of the intensity and typology of element at risk.

\section{Description of the methodological model and its application to a case study}

Our methodological model for flood damage estimation can be summarised in the following steps (Figure 1):

- $\quad$ Event description: definition of flood parameters (flooded area and water level). This definition will be enabled by real-time measurements or by event simulation with a hydraulic model.

- Damaged assets identification as a consequence of the flooded area.

- Evaluation of the degree of damage to the exposed elements as a function of event magnitude identified from measurement of floodwater depths of an event.

- Attribution of an economic value to exposed assets.

- Quantification of economic loss by multiplying economic value of damaged assets and degree of damage.

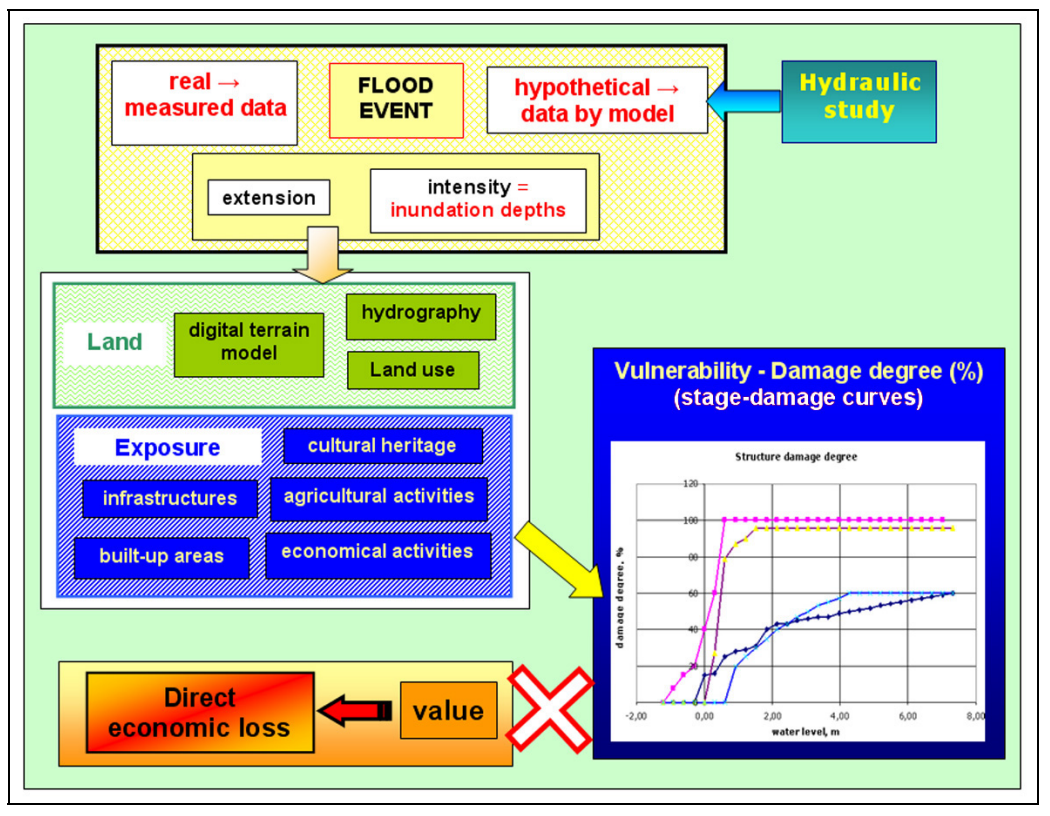

Figure 1: Conceptual model for flood damage assessment. 
The method can be used to estimate the damage from the impact of floodwaters on exposed elements (direct damage) and to quantify the resulting economic loss (tangible damage). Indirect and intangible damage assessment is beyond the scope of this model.

During the development of the model, a case study was set up to test and calibrate the methodology. The Boesio Stream basin (Varese Province, Lombardy, Italy) (Figure 2) was chosen as the study sample because of its relatively small area $\left(45 \mathrm{~km}^{2}\right)$, intense human pressure, availability of territorial data and historical information about the damages from past catastrophic events, a recent severe flooding event for which information about damage was well documented. The method was applied to the case study to estimate flood damage to structures. Damage to agriculture and mobile goods was not taken into account because that would have required data not available for the area and additional time for research and data processing.

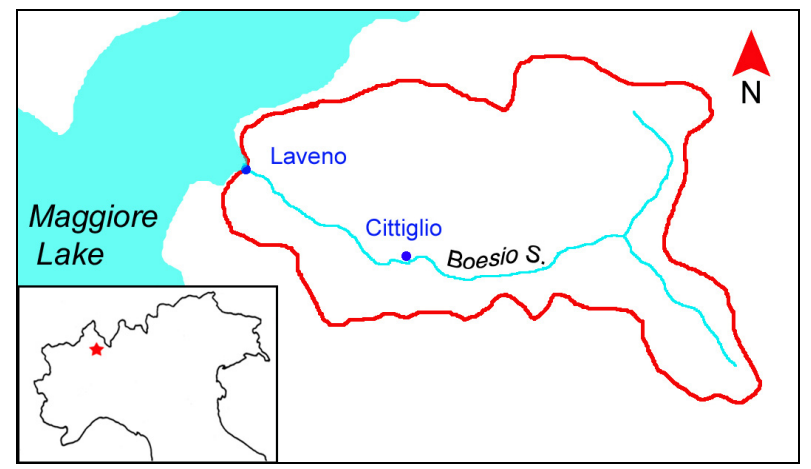

Figure 2: Geographical sketch of the Boesio basin.

\subsection{Geodatabase}

Application of the methodology is bound by data availability for a study area; these data should be organised into a GIS database.

The data can be collected and classed in two typologies:

- layers containing geographic information about the territory: topography, altimetry (DTM), hydrography, hydrology;

- $\quad$ layers pertaining to anthropic presence, exposed assets and land use.

As a rule, the more detailed the information, the greater the precision in potential loss assessment.

\subsection{Typology of flood events}

The method can be applied to two types of floods:

- $\quad$ Real events: flooded area and inundation depths measured in the field. The method allows a quick estimate of the approximate damage extent during or immediately after an event ("nowcasting").

- Event scenarios based on hydrological analyses. The event's 
characteristics are obtained through hydraulic models, and the methodology is applied for forecast purposes to predict the consequences of a given future event.

In May 2002 the study area was struck by a severe hydrometeorological event. The Boesio Stream and its tributaries overflowed, involving built-up and rural areas and causing heavy damage to houses and factories. This flood event was chosen as the reference event to calibrate and test the method, a back analysis was performed to verify process validity and reliability of the results. For this reason, the event was thoroughly investigated using surveys, interviews with local inhabitants, and data acquisition from the local administration databases. The inundation limits and the levels reached by flood waters were identified and graphically represented as GIS layers. Data about event-related damage and losses were collected and processed. For each inundated structure information was collected about: structure typology and use, ground floor surface area, building value, hydrometrical level reached by the floodwaters on the ground floor, damage to the structure and consequent economic loss.

\subsection{Hydrologic-hydraulic study}

Application of the methodology requires knowledge of a flooded area and of event intensity (floodwater level). The definition of flooded area and water level is organised into 4 phases.

1) Data collection. Input data of the hydrological study are: discharges or rainfalls measured in the sample catchment basin (and/or the adjoining basins) during the event; historical series of discharge or rainfall measures.

The process is easier and more reliable if the discharge measures are available; otherwise, additional calculations are required to obtain rainfall-intensityduration curves for an area under study, as was the case of the Boesio Stream basin.

2) Hydrological study. The purpose of hydrological analysis is to determine the real or hypothetical flood discharge, which should be assumed as a reference discharge for damage calculation. In the study area, a rainfall-runoff model was defined to calculate peak discharge values corresponding to given return periods.

3) Hydraulic modelling. The hydraulic model permits the determination of the hydrometrical levels of the riverbed and, in case of overflowing, the definition of flooded areas and of floodwater depths. Preliminary information required for the hydraulic model are:

a) peak discharge values measured or determined using a rainfall-runoff model;

b) morphological data about the riverbed and flood-prone areas: in the study area a detailed topographic map was generated and 237 valley bottom cross-sections were defined;

c) contour conditions.

Hydraulic modelling was carried out using the calculated discharges (corresponding to a given rainfall return period): the absolute free water level was obtained as output that went into defining the floodable areas.

4) Definition of event scenarios. A detailed hydraulic analysis was performed on a critical reach of the Boesio Stream in the Cittiglio territory. Two event scenarios were created corresponding to ordinary and extraordinary floods. A 
comparison between the floodable area generated by the model and the May 2002 flooded area shows that results fit well with the real situation.

\subsection{Building vulnerability and stage-damage curves}

By definition, vulnerability can be described as the degree of damage to a group of elements at risk resulting from a natural event with a given intensity. The degree of flood-induced damage on structures is determined by many factors, including water level, flow speed, quantity of suspended and floating load, contaminants in the water, and flood duration. The published literature (Van der Sande [3]; Queensland Government [4]; FEMA [5]) reports that considering the depth of flooding as the only indicative factor for flood event magnitude is a widely shared simplifying assumption.

Given a particular type of exposed element, a relationship can be defined between the depth of flooding and the loss incurred as a percent of the element's total worth (damage degree) (Figure 3). Couples of values inundation depth damage degree describe the direct effect of floodwater on different types of exposed elements. They define curves which are usually referred to as stagedamage curves (also called loss functions or vulnerability functions) and estimate the damage level as a value between 0 (no damage) and 1 (total destruction). These are crescent functions and are not necessarily continuous: multiple discontinuity curves are also used.

Each curve should be studied to describe the effect of floodwaters on a particular type of exposed element (distinguishing building construction type and dimension, road importance, etc.) and it can be used to simulate damage for potential future inundations. However, extrapolating data collected from place to place because of differences in building type and content can be problematic. For this reason, different curves should be created for different geographical areas and then applied to limited homogeneous territories.

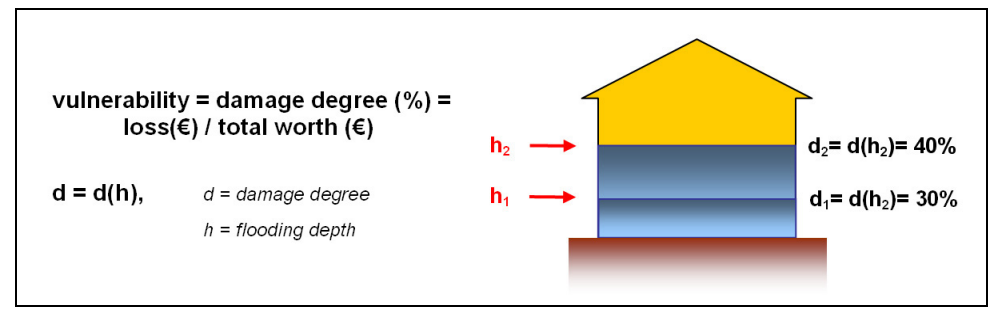

Figure 3: Given a particular type of structure, different water levels are uniquely related to different damage degrees.

The data gathered for each inundated structure during the May 2002 flood event in the Boesio Basin were employed to develop stage-damage curves.

Residential buildings with a basement constitute the bulk of the structures damaged during the May 2002 flood. For this reason, a stage-damage curve was generated only for this type of building (Figure 4). An empirical approach was 
followed, using the information on losses measured after the flood combined with estimates of water depth. The curve describes the effect of floodwaters on the structure (masonry, floor, doors, windows, equipment, installations), without considering mobile goods.

For each building the damage degree was calculated by dividing the economic loss sustained to repair structural damage by the value of the ground floor plus basement (see section Economical evaluation of buildings).

\section{damage degree $(\%)=\operatorname{loss}(€) /$ [ground floor value $(€)+$ basement value $(€)]$}

About 100 couples of values of water level - damage degree were plotted on a dispersion diagram, and a stage-damage curve was obtained by linear interpolation. The flood depth to develop the curves includes both flooding to the basement level of the structure (negative values) and the depth of water above the ground surface (positive values).

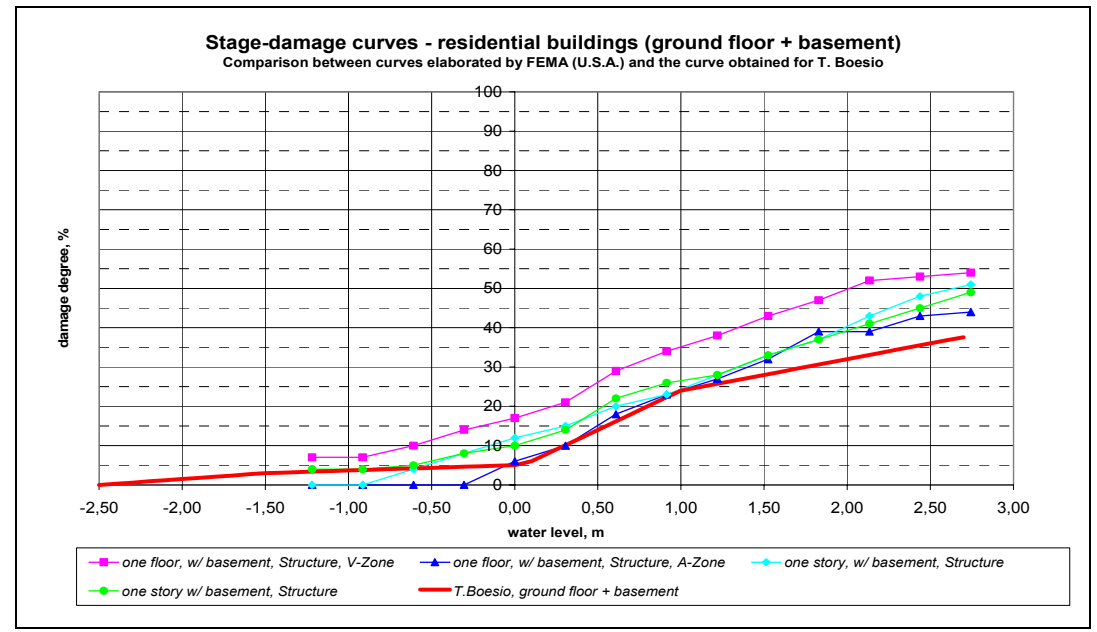

Figure 4: Stage-damage curves for residential buildings. Comparison between curves elaborated by FEMA in the U.S. (after FEMA [5], mod.) and the curve obtained for T. Boesio.

\subsection{Economic evaluation of buildings}

A preliminary evaluation of the elements exposed to hydraulic risk is essential for damage quantification in either a nowcasting or a forecasting application of the model.

With regard to buildings, a punctual evaluation was applied, considering each structure in the flood-prone areas. Estimation of buildings and contents value is based on a knowledge of the structural type of building and its use. For this, the study area database requires a layer containing the delimitation and the 
characteristics of all buildings (building use, typology, number of floors, presence or absence of basement, ground floor surface area).

In Italy, the unit value of buildings $\left(€ / \mathrm{m}^{2}\right)$, considering only the structure and not the content, is given by the Banca dati delle quotazioni immobiliari, (real estate and property price database) published by the Osservatorio del Mercato Immobiliare dell'Agenzia del Territorio (district real estate market analyst services) [6]. The estimation of a building's unit value is based on its geographical location, use and typology. The database furnishes a minimum and a maximum value for each type of building and is updated every 6 months.

The database was used to assign a unit value to the buildings in the Boesio basin, calculating the average between the minimum and the maximum value estimated for each type of building.

In the Boesio basin the ground floor and the basement are the only parts of a building that are vulnerable to flood damage. In general, Boesio floodwaters reach a maximum height of 2 meters above the ground. For this reason, for each building in the flood-prone area, only the value of the ground floor and the basement was considered in estimating exposure. The value of the ground floor was calculated by multiplying the ground floor surface area by the unit value. Following FEMA evaluation criteria [5], the basement value was expressed as a percent of the total structure value: for the study area the basement (cellar, boiler room, garage) value was estimated to be about $25 \%$ of the ground floor value.

\subsection{Calculation of expected building damage}

During the development of the methodology, a computational model for the assessment of flood expected damage was elaborated in a GIS environment. Raster information layers in grid format were employed for this purpose. Using the ArcGIS software and its Spatial Analyst extension a territorial analysis was performed by operating between different raster datasets to obtain information from superposition and combination of themes.

The computational model was applied to the case study to calculate the economic damage to residential buildings due to the May 2002 flood in Cittiglio.

The following information layers stored in the database were used:

- $\quad$ digital terrain model;

- water surface elevation (expressed in $\mathrm{m}$ asl), calculated by hydraulic modelling. In this study calculated water depth values instead of those measured on field after the May 2002 flood were used because they were more uniformly distributed. Moreover, not enough floodwater levels were available for all builtup areas and buildings to perform a reliable interpolation.

- polygonal layer of built-up areas, with buildings classified by use, building mode and economic unit values in $€ / \mathrm{m}^{2}$ (ground floor unit value + basement unit value).

All the layers in shapefile format were converted into a grid format; the same cell size was set for each in order to obtain a one to one ratio between the cells. This bears direct matching between cells from different grids and enables operations between grid values. Considering the resolution of the data source, a cell dimension of 1 metre was chosen in the conversion phase from shapefile to 
raster. This cell size is suitable for representing any object or land form with sufficient detail.

The built-up area shapefile was first divided into different layers, each illustrating structures belonging to a single use category (residential, production, trade, etc.). Only the shapefile of residential buildings was afterwards used.

For all flooded locations, the ground surface elevation grid (DTM, m asl) was subtracted from the calculated water surface elevation grid (expressed in $\mathrm{m}$ asl), resulting in a grid that illustrates the floodwater levels above ground surface (m). Calculation of the expected economic loss was later carried out by the operations illustrated in Figure 5.

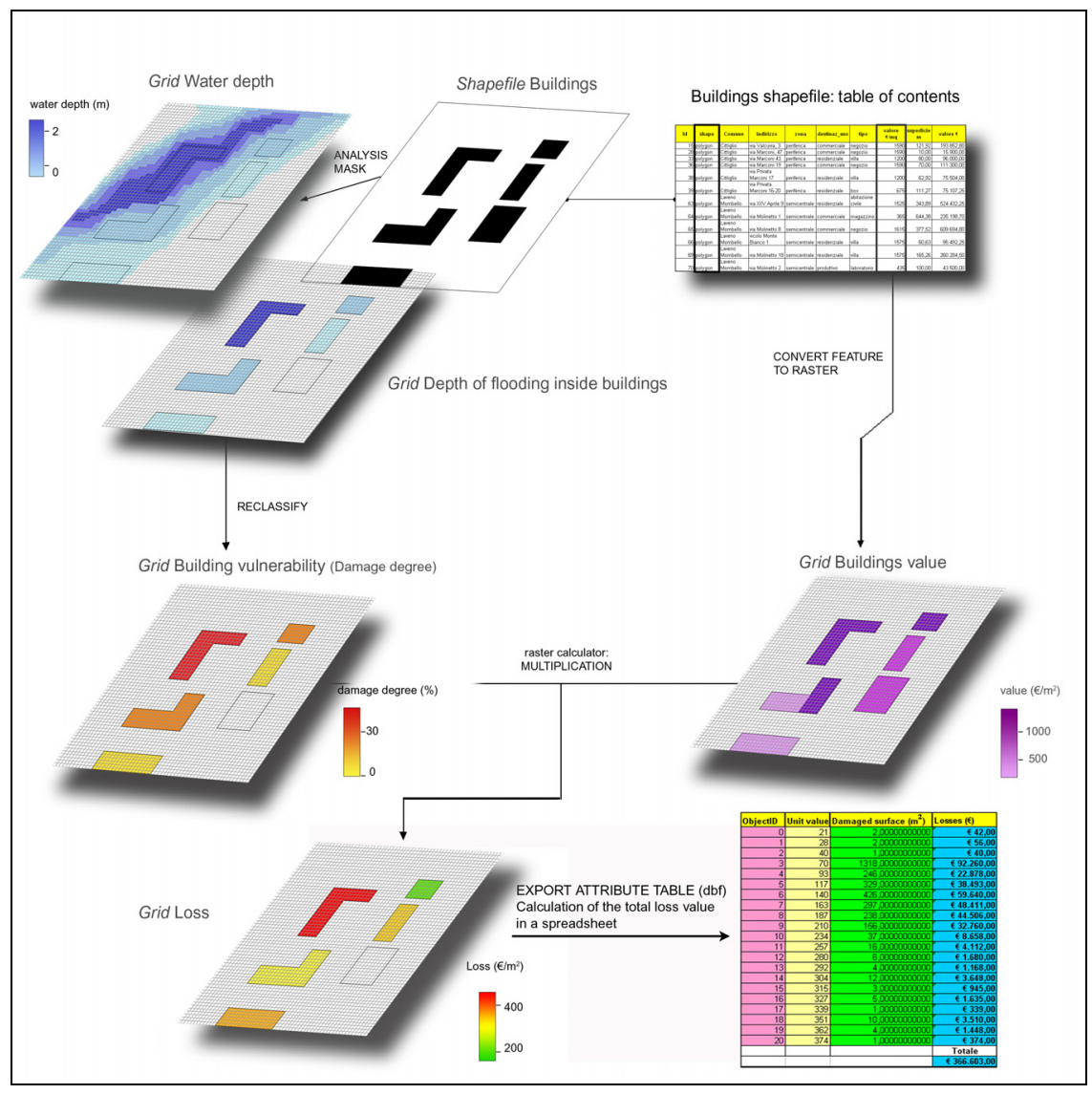

Figure 5: Calculation of the expected flood damage loss.

The resulting Loss grid defines the potential loss values in each cell; its attribute table contains the loss value classes and the related number of cells. 
The related table of the Loss grid was exported and processed on a spreadsheet. Thus, using simple addition and multiplication, it was possible to obtain an appraisal of the loss value for the residential buildings in Cittiglio.

The calculated loss amounts to $€ 181.000$. Losses for the Boesio flood-related damage to the structure of residential buildings and officially declared by Cittiglio Municipality amounted to $€ 110,000$. Overlooking the approximation of the calculation model and the need to calibrate the method with other case studies, the difference between the real loss and the calculated value is ascribable to the damage assessment criteria. Only losses over $€ 2500$ for damage to principal residences were considered refundable and so reported, making a total loss of $€ 110,000$ certainly an undervalued sum.

\section{Conclusions}

The proposed methodology meets the need of public administrators to achieve a fast, though approximate, damage estimation after a disaster. The method was designed for being imported to different geographical contexts, also where different base information is used. It could be used either as a forecasting tool to define event scenarios or for "real-time" damage assessment after a catastrophe. These features make it a useful tool for decision-making in land management.

\section{Acknowledgement}

This research has been carried out in the DAMAGE Project, Interreg IIIB MEDOCC. Group leader: Govern de les Illes Balears, Direcció General d'Emergències.

\section{References}

[1] Damage Project, Développement d'Actions pour le Marketing et la Gestion post-évènements, Programme INTERREG IIIB Medocc, 2004, http://130.206.132.248/webdamage/index.en.html

[2] GEORISK, Risk management terminology, 3 pp., 2004 http://www.georisk.com/terminol/termirisk.html

[3] Van der Sande, C., River flood damage assessment using IKONOS imagery, E.C. Joint Research Centre \& S.A.I., 77 pp. , 2001

[4] Queensland Government, Disaster loss assessment guidelines, Illycroft Pty Ltd, 111 pp., 2002

[5] FEMA, Hazard MH - Multi-hazard Loss Estimation Methodology, Federal Emergency Management Agency, 2003

[6] Agenzia del Territorio - Osservatorio Del Mercato Immobiliare, Banca Dati delle Quotazioni Immobiliari, Agenzia del Territorio, 2005 www.agenziaterritorio.it/servizi/osservatorioimmobiliare. 